\title{
El género pesa más que una arroba
}

\section{Ellos, Ell@s o Ellas y Ellos}

Con frecuencia muchos nos encontramos, a la hora de escribir y hablar, con la dificultad de hacerlo evitando expresiones sexistas. Algunas personas, y no sólo las feministas, critican el hecho de que el lenguaje utilizado sobreabunda con epítetos masculinos, y si se habla de los niños, los trabajadores, los campesinos y los estudiantes no queda claro si los sujetos son igualmente (?) las niñas, las trabajadoras, las campesinas y las estudiantes. El lenguaje está sobrepoblado de imágenes masculinas a fuerza del imperativo masculino de la sintaxis. No pocas veces algunos — sí, algunos, no algunas - responden ya sea ridiculizando el reclamo diciendo, "de acuerdo: para que todos y todas queden contentos y contentas seremos más cuidadosos y cuidadosas con las palabras y los palabros"; o bien señalando que no ven por qué tanta insistencia sobre algo sin ninguna trascendencia y de tan poca monta ya que cuando decimos "ellos" debe entenderse, obviamente, que también están incluidas "ellas".

Un segundo grupo que quiere ser sensible a la perspectiva de género, aunque sin comprender enteramente la razón fundamental de la protesta, quiebra la palabra culpable con el signo de la arroba (@) y, sometida la palabra, ofrece esta novedosa solución al problema. Así, hablan de ell@s y de 1@s niñ@s. Y el lenguaje queda sobrepoblado de símbolos que dificultan la pronunciación misma y que, por lo menos pictóricamente, el ambiente de lo femenino parece estar todavía engullido por lo masculino.

Todavía existe un tercer grupo que repara que la disparidad de género y su posible rectificación no está en buscar correcciones en el lenguaje sino en el cambio de conductas por medio de las cuales de manera real, no simbólica, se vaya buscando cotidianamente la igualdad. La lucha, aducen, hay que librarla en lo legal, en el ámbito laboral y en el de las relaciones interpersonales, incluidas las de pareja. Dejarían el lenguaje intacto pues lo considerarían secundario a la problemática. Aunque más iluminados que el primer grupo y sin emular la insensibilidad de aquél, desconocen que el lenguaje -la conversación y la palabra escrita- es lo que esencialmente nos define ${ }^{1}$, es donde se encuentra lo típicamente humano, y que lo simbólico es profundamente transformador. Sin llegar a entender lo que el lenguaje dice y cómo lo dice no se pueden esperar los cambios de conducta deseados de manera consistente. Su postura cabalga ambi-

1. Para un tratamiento más extenso sobre lo fundamental de la conversación como primer determinante de lo humano, ver Billig, M., Arguing and thinking: A rhetorical approach to social psychology. Cambridge, Gran Bretaña: Cambridge University Press, 1987; Harré, R., Personal being: A theory of individual psychology, Cambridge, MA: Harvard University Press, 1984; Shotter, J., Social constructionism and realism: accuracy or adequacy? Theory \& Psychology, 1992, Vol. 2, pp. 175-182; y también Wetherell, M. y Potter, J., Mapping the language of racism. Discourse and the legitimation of exploitation, Londres: Harvester Wheatsheaf, 1992. 
guamente entre las de los dos grupos que hemos identificado sin ser claramente sintética.

El primer grupo, aquéllos que no ven razón de peso para cambiar el lenguaje hablado y escrito, adjudica un celo desmesurado a grupos minoritarios que quieren cambiar, sin más, una convención lingüística establecida, ágil, probada, que goza de amplia aceptación y está sancionada por las más respetadas academias de la lengua. En consecuencia, resisten tal "embate" al lenguaje con igual celo, quizás intuyendo que está en juego algo más que una expresión lingüística. El segundo grupo, más sensible a la diversidad al hacer más engorrosa la expresión, inconscientemente le da la razón al primer grupo, quienes aceptan sonrientes la derrota de aquellas personas que desean que el lenguaje sea más inclusivo, pues ni aún sus simpatizantes son capaces de argüir convincente y elegantemente. El tercer grupo sencillamente se sustrae de la contienda y en no pocas ocasiones brinda su apoyo epistemológico a la facción menos estridente del primer grupo, pues tampoco ve la necesidad de alterar las reglas del juego discursivo.

Las posturas parecen estar delineadas: un grupo se apega a un lenguaje rígido, otro lo vuelve impronunciable, y todavía un tercero estima que la controversia hace que "se riegue fuera de tiesto"; un grupo pone en evidencia su insensibilidad $\mathrm{e}$ intransigencia, otro muestra más destreza en comunicarse por medio de Internet que sensibilidad de género, mientras que otro desestima la fuerza evocadora del lenguaje y las imágenes que éste construye. Lo cierto es que nos encontramos ante un problema de difícil solución: por un lado, en los albores del Siglo XXI no podemos conservar la misma expresión sexista que hemos tenido en el lenguaje por tanto tiempo y, por el otro, las nuevas sensibilidades de género, correctamente asumidas, deberían garantizar cierta agilidad al lenguaje que ćste justamente exige. No es aquí donde le vaya- mos a dar solución al problema. Sencillamente quisiera apuntar algunas razones del por qué del problema de la torpeza del lenguaje a la hora de intentar ser inclusivo. La razón reside en el lenguaje mismo y en su proceso de representación ${ }^{2}$.

\section{¿Voz acomodaticia o transformadora?}

El lenguaje y, por lo tanto, el discurso humano, no es meramente una serie de reglas por medio de las cuales se van tejiendo las oraciones asegurándose de que exista concordancia de género, número y tiempo entre sus distintos elementos, sino que es un medio de vida cognitiva y de comunicación. El lenguaje no es sencillamente el espejo de la realidad o una herramienta neutral, sino que acentúa las características de los objetos que representa y subraya ciertos significados de la situación que describe ${ }^{3}$. En virtud de esta representación, el lenguaje estructura tanto nuestra propia experiencia de la realidad como la experiencia de aquellas personas con las que nos comunicamos. El habla y el lenguaje escrito no cumplen ni simple ni principalmente una función expresiva, como tampoco la comunicación es una mera transmisión de un mensaje preformado que se origina en la persona transmisora y termina en la persona que escucha. La comunicación, en lin, no es el flujo de palabras entre el locutor o locutora y el colocutor o colocutora, aun cuando introduzcamos el concepto de la retroalimentación.

Tanto el habla como el lenguaje escrito son principalmente prácticas culturales dentro de las cuales quedan constituidas aquellas realidades con las que nos relacionamos, es decir, son constitutivos de la realidad. La problemática de la incorporación de la perspectiva de género, por lo tanto, no queda resuelta con agregar sencillamente "las" cada vez que se dice y se escribe "los", ni mucho menos con hacer el lenguaje escrito todavía más torpe y el hablado impronunciable. Estas solucio-

2. Las ideas de este ensayo descansan en los trabajos de Bem, S. L., The lenses of gender, New Haven, CT: Yale University Press, 1993; Doyle, J. A. y Paludi, M. A., Sex and gender. The human experience, 2da Edición, Dubuque, IA: Wm. C. Brown Publishers; y Sampson, E.E., "Identity politics. Challenges to psychology's understanding", American Psychologist, Vol. 48, 1993, pp. 1219-1230.

3. Ver Edwards, D. y Potter, J., "Language and causation: A discursive action model of decription and attribution", Psychological Review, Vol. 100, 1993, pp. 23-41; Gergen, K. J., "The language of psychological understanding". En H. J. Stam, R. B. Rogers y K. J. Gergens (Eds.). The analysis of psychological theory: Metapsychological perspectives, Nueva York: Hemisphere, 1987, pp. 115-129; Shotter, J., Knowing of the third kind, Utrecht, Países Bajos: Universidad de Utrecht, 1990; y también Wertsch, J. V., Voices of the mind: A sociocultural approach to mediated action. Cambridge, MA: Harvard University Press, 1991. 
nes hacen del género un simple agregado al discurso puesto que asumen una estrategia acomodaticia que continúa sirviendo los intereses de los grupos dominantes en vez de ser una respuesta genuinamente transformadora para aquellas personas que buscan que su propia voz se escuche. En definitiva, esta solución es acomodaticia porque el nuevo elemento que se incorpora no se considera constitutivo del fenómeno de interés.

Como el mismo término "acomodaticio" indica, sencillamente se agrega a la antigua convención sin cambiar primordialmente nada. El acomodo protege al mundo dominante de la transformación y no quedan desafiadas de manera fundamental las cuotas de poder repartidas. El mundo que queda signado por el discurso continúa siendo en esencia masculino. Curiosamente, dejar que el discurso agregado donde se obliene tal representación sea lo aceplable permite a las mujeres hablar pero sólo pidiendo permiso, disculpándose por la torpeza que introduce su reclamo, y con el lenguaje del discurso dominante: "si para ser escuchada debo de hablar de la forma que me propones, entonces sólo puedo ser escuchada si hablo como tú, no como yo. En vez de ser iguales constructores de la realidad permanezco encerrada en un juego discursivo que asegura tu ventaja continuada y mi desventaja consuetudinaria"4.

Pareciera que para que se escuche a la mujer hablar sobre su mundo, su problemática y sus experiencias, ésta tiene que hablar como hombre, construyéndose con las categorías con las que ha sido construida por los intereses, miedos y deseos masculinos dominantes y perdiendo su particularidad y especificidad. Cuando el guión de esta conversación está labrado cuidadosamente de tal ma- nera que queda representado de manera implicita el punto de vista y el interés de un grupo doml. nante, el simple hecho de tener una parte en ese guión no equivale a un diálogo verdadero donde el punto de vista, los intereses y la especificidad del grupo minoritario estén tomados en cuenta. Al hablar sobre el lenguaje hablado, el psicólogo ingles, Rom Harré, dice que la conversación provee el trasfondo intransigente a toda acción humana $y$ que nos introduce a un mundo tan robusto como el flujo de la energía electromagnéticas ${ }^{5}$. Como se comprenderá, hay mucho que está en juego. De allí las dificultades tanto inherentes al lenguaje como las recalcitrantes de algunos estamentos.

Es claro. La prácticas culturales y psicológicas actuales niegan a cierto grupo la capacidad de ser escuchadas y de hablar a su modo, con sus propios términos, reflejando sus propios intereses e idiosincrasias y reflejan el ejercicio del poder de aquéllos que dictan los términos con los cuales se sale al encuentro de las realidades psicológicas y sociales. Dicho de otra manera, el discurso entre y sobre personas y el lenguaje que esto produce son recursos importantes en el ejercicio del poder. Por eso alguien ha definido el lenguaje como un sistema simbólico utilizado por los poderosos para rotular, definir y jerarquizar. Baste observar la práclica de aquéllos que detentan el poder político para percatarnos de lo cierto de esta observación. Estos grupos buscan controlar la información que se puede diseminar y a la cual tienen acceso los que consumen estc producto lan característicamente humano; tejen las parábolas y metáforas con las cuales se entiende la realidad social, y fabrican los milos que cautivan y dinamizan la conciencia ${ }^{6}$. Es decir, estos grupos buscan si no adueñarse de la

4. Este es el tipo de conversación y lenguaje que algunas feministas y psicólogos sociales constructivistas dicen que imposibilita la incorporación de la mujer a las relaciones interpersonales como persona micmbro de pleno derecho y no como un cuasimiembro. Para una discusión más elaborada de este tema ver Braidoti. R., Patterns of dissonance: A study of women in contemporary philosophy, Nueva York: Routledge, 1991; Butler, J., Gender rouble: Feminism and the subversion of idensity. Nueva York; Routledge, 1990; Irigaray. L.. Specultum of the other woman, Ithaca, NY: Cornell University Press, 1985 [Trabajo original publicado en 1974]; Gannon, L., Luchelta. T., Rhodes. K., Pardie. L. y Segrist. D.. "Sex bias in psychological research; Progress of complacency”. American Psychologist, Vol. 47, 1992, pp. 389-396; y MacKinnon, C.A.. Toward a feminist theory of state, Cambridge, MA: Harvard University Press, 1989.

5. Harre, R., "What is real in psychology: A plea for persons", Theory \& Psychology. Vol. 2, 1992, pp. $153-158$. Ver también a Sarbin, T. R., Narrative psychology: The storied nature of human conduct, Nueva York: Praeger, 1986.

6. Es interesante notar que a juicio de algunos historiadores, investigadores y lïlósofos de la ciencia, la ciencia misma refleja los valores sociales e intereses de los grupos dominantes de la sociedad. Ver a Buss, A. R., "The structure ol psychological revolutions". Journal of the History of the Behavioral Sciences, Vol. 14, 1978, pp. 
palabra y posesionarse de la conversación, por lo menos dirigirla o controlarla. Al controlar la voz, se fijan las condiciones de vida de los demás y se determinan su identidad y subjetividad. Para despejar cualquier ambigüedad hay que dejar meridianamente claro que no descubrimos el mundo objetivo tal como el positivismo lógico quisiera hacernos creer. No; nos lo inventamos y lo inventamos macho.

\section{La construcción discursiva de la identidad}

Nuestra experiencia no refleja directamente lo que está fuera de nuestra conciencia, sino que por medio del lenguaje la ordenamos y organizamos identificando ejes aglutinadores que, como imanes, estructuran ese campo psicológico del cual hablaba Kurt Lewin ${ }^{7}$. No observamos pasivamente la realidad y la decimos sino que activamente construimos significados que enmarcan y organizan nuestras percepciones y experiencias. De allí que nuestro entendimiento de la realidad sea una representación, es decir, una construcción nueva de la mente agéntica y no una imagen o fotografía de lo que hay allí afuera. La crítica del uso sexista del lenguaje es precisamente esto: la representación de la realidad con categorías y ojos masculinos y la delineación simbólica de lo masculino como definitorio y lo femenino como opositor, contestatario y, por ende, secundario. El lenguaje rígido o el impronunciable simplemente encubren la realidad.

El encubrimiento tiene la finalidad de asegurar la invisibilidad de lo femenino o reducir su presencia a una mera contraparte. Se aseguran así dos cosas: el privilegio de asentar la agenda discursiva y la percepción de que el lenguaje inclusivo resulta de la benevolencia masculina. Esta benevolencia, obviamente, puede quedar suspendida cuando el hombre lo estime conveniente; benevolencia que se antoja más como amenaza pues pende como verdadera espada de Damocles sobre la conciencia femenina ${ }^{8}$.

Como venimos diciendo, una de las funciones principales del lenguaje es dar forma y coordinar la acción social tal como famosos psicólogos ${ }^{9}$ y filósofos ${ }^{10}$ han argumentado de manera persuasiva. Una vez que las designaciones linguúísticas se convierten en convenciones, éstas tienen el enorme poder de restringirnos y señalarnos las características importantes y determinantes de aquella realidad signada. Las palabras son obras no sólo en el sentido de que lo que decimos sobre lo que hacemos le da inteligibilidad a nuestro obrar sino, de manera importante, en el sentido de que los mismos objetos y sujetos de nuestro mundo son constituidos como tales en y a través de nuestro discur-

57-64; McHugh, M. C., Koeske, R. D., y Frieze, I. H., "Issues to consider in conducting nonsexist psychological research. A guide for researchers", American Psychologist, Vol. 41, 1986, pp. 879-890.

7. Ver Lewin, K., La teoría de campo en la ciencia social, Buenos Aires: Paidos, 1951/1978.

8. Plantemiento similar se puede hacer desde la perspectiva de otros grupos que no gozan de mayor poder y que reclaman igualmente su voz. Así, los países del llamado Tercer Mundo desafían la dominación de la perspectiva Eurocéntrica y reclaman una perspectiva autóctona en el análisis psicológico (Ver Moghaddam, F., "Modulative and generative orientations in psychology: Implications for psychology in the three worlds", Journal of Social Issues, Vol. 46, 1990, pp. 21-4I; y Montero, M., "Ideology and psychosocial research in third world contexts", Journal of Social Issues, Vol. 46, 1990, pp. 43-55); los grupos de homosexuales y lesbianas desafían la dominacion opresiva heterosexual plasmada en la creencia de que los valores heterosexuales son superiores y/o más naturales que los homosexuales (Ver Morin, S. F., "Heterosexual bias in psychological research on lesbianism and male homosexuality", American Psychologist, Vol. 32, 1977, pp. 629-637; Morin, S. W., "Removing the stigma: Fifteen years of progress", American Psychologist, Vol. 46, 1991, pp. 947-949; y Herk, G. M., Kimmel, D. C., Amaro, H. y Melton, G. B., "Avoiding heterosexist bias in psychological research", American Psychologist, Vol. 46, 1991, pp. 957-963); y las culturas afroamericanas impugnan el racismo consuetudinario de las prácticas culturales y psicológicas actuales (Ver Graham, S., "Most of the subjects were White and middle class: Trends in published research on African Americans in selected APA journals, 1970-1989", American Psychologist, Vol. 47, 1992, pp. 629-639; y Williams, P. J., The alchemy or race and rights, Cambridge, MA: Harvard University Press, 1991).

9. Ver Bruner, J., "Life as narrative", Social Research, Vol. 54, 1987, pp. 11-32; Mead, G. H., The social psychology of George Herbert Mead, Chicago: Chicago University Press, 1834; y Vygotsky, L. S., Mind in society: The development of higher psychological processes, Cambridge, MA: Harvard University Press, 1978.

10. Ver Foucault, M., Discipline and punish: The birth of the prison, Nueva York, Random House, 1980; y Wittgenstein, L., Philosophical Investigations, Oxford, Gran Bretaña: Basil Blackwell, 1953. 
so. Este accionar puede pasar desapercibido por el que construye y sienta las reglas del juego, pero difícilmente pasa desapercibido por aquélla que es construida y que se tiene que ajustar a las reglas de un juego que le ha tocado jugar en desventaja. En cstas prácticas discursivas queda constituido aquello que llegamos a aceptar como real. Como muchos psicolingüistas y sociolingüistas llegan a afirmar, cuando creamos las categorías de nuestro mundo y éste lo experimentamos de acuerdo con ellas, no estamos aplicando etiquetas categóricas preexistentes a esas categorías" ${ }^{11}$ Más bien, las calegorías para personas y objetos se diseñan para que ćstas desempeñen determinadas acciones sociales. Dicho de manera sencilla, cl discurso - hablado y cscrito - no sólo es una forma de ver, sino una forma de construir lo que se ve.

\section{Género y poder}

Hemos aludido al hecho de que el grupo que controla el lenguaje tiene poder pues controla lo qué y cómo se dice e influye en la imaginación y representación de la realidad social. Veamos este punto con más alención. El que controla el lenguaje construye un mundo dividido. Pero estas divisiones no anteceden al discurso mismo; son consecuencia, efecto, del proceso discursivo donde está en juego el poder. Las categorías de identidad, por medio de las cuales nuestro mundo está dividido dualista y opositoriamente entre hombre y mujer, cumplen la misión de asegurarse los privilegios de unos y la susientación de una manera de pensar e interactuar con el mundo. Aquellas personas que sostienen que la división hombre-mujer, masculino-femenino, tiene su raíz incontestable en cromosomas. hormonas y lo genital son las que en realidad "riegan fuera de tiesto". Estas características hiológicas han sido seleccionadas discursivamente con la finalidad de mantener la separación cercana a lo reproduclivo y así asegurarse de que los hombres y las mujeres se mantengan en "el lugar que les corresponde".

Tomemos un ejemplo para ilustrar cómo la subjetividad está determinada por las desigualda-

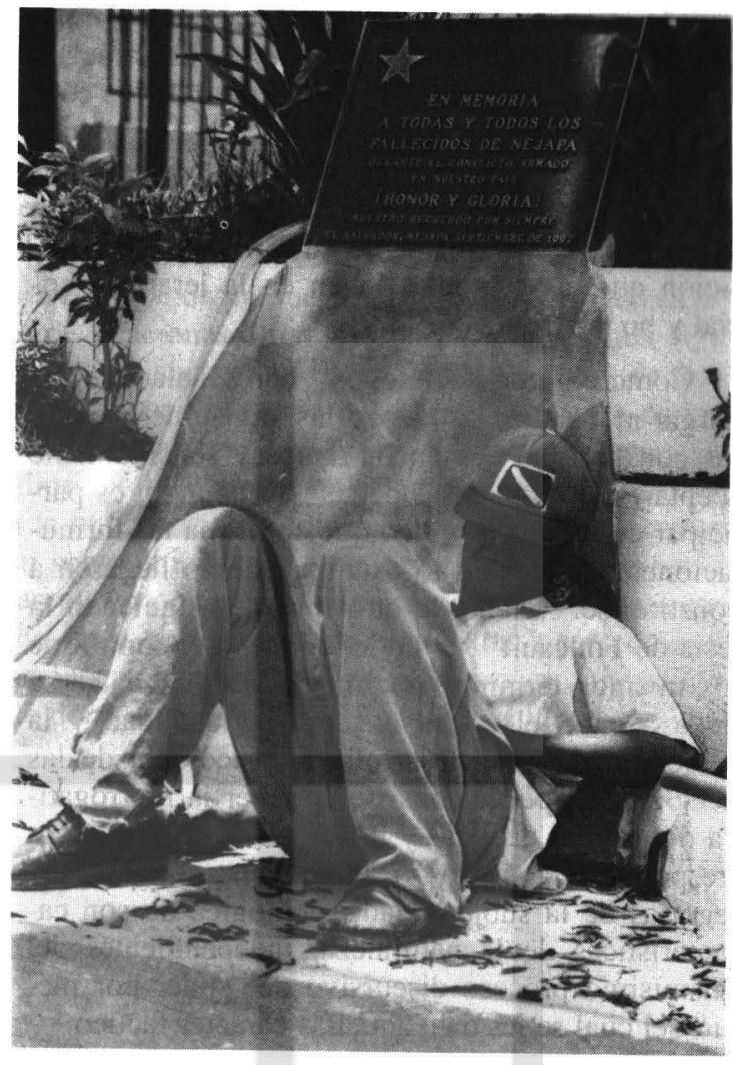

des sociales y la disparidad en cuotas de poder y no reflejan diferencias inherentes entre hombres y mujeres. Algunos consideran que la racionalidad es esencialmente una cualidad masculina y el énfasis en las relaciones caracterizan lo femenino ${ }^{12}$. Sin embargo, las diferencias que se observan entre hombres y mujeres liene que ver más con la posición que ambos tienen en el orden social. El énfasis que ponen los hombres en la racionalidad está basado en el hecho de que estos principios fueron promulgados para promover sus intereses; mientras que el énfasis que las mujeres ponen en las relaciones se explica como estrategia para reivindicar algunos derechos. Normalmente aquellos que detentan el poder aluden a las leyes, el control, la disciplina y la racionalidad, mientras que aquellos que no lo tienen apelan a las consecuen-

11. Ver Edwards. D., "Categories are for talking: On the cognitive and discursive bases of categorization", Theory \& Society, Vol. 1, 1991, pp. 515-542; y Gilbert, G. N. y Mulkay, M. J., Opening Pandora's box: A sociological anclysis of scientists' discourse, Cambridge, Gran Bretaña: Cambridge University Press, 1984.

12. Tal es el caso de la crítica que hace Carol Gilligan a la teoría de desarrollo moral de Lawrence Kohlberg. Ver Gilligan, C., In a different voice: Psychological theory and women's development, Cambridge, MA: Harvard University Press, 1982. 
cias de las relaciones interpersonales, a la compasión y a la solidaridad. Cuando las mujeres juegan un papel dominante - como en el caso de los conMictos madre/hijo o hija-, las madres acuden a las reglas mientras que la prole apela a la comprensión y al sentimiento de simpatía. Tal cambio sugiere que estas diferencias se explican por la posición que las personas tienen en la jerarquía social y no por el género ${ }^{13}$.

Como algunos sociólogos ${ }^{14}$ han señalado, el no hurgar ni desafiar las categorías, divisiones y objetos con los que nos encontramos y sencillamente aceptarlas como "cosas dadas" del mundo, es participar en un acto político que confirma las formulaciones actuales al no examinar cómo llegaron a constituirse. Dicho de otro modo, y siguiendo la tesis de Foucault ${ }^{15}$, el poder conlleva el control de los mismos términos por medio de los cuales se lleva a cabo el discurso sobre la identidad y la subjetividad, y se desarrolla la psicología de las personas. El poder consiste en tener la prerrogativa de asignar el lugar y la subjetividad que le corresponde a las partes en la conversación. Las categorías de la subjetividad psicológica no son características de la naturaleza, independientes del mismísimo proceso discursivo del poder por medio del cual se les da a aquéllas carácter fáctico:

"El proceso de categorización y, por ende, de la psicología de la categorización, no reside sólo en la mente sino ... dentro del discurso como parte del ámbito colectivo de negociaciones, debates y de una lucha argumentativa e ideológica"16.

Sólo contribuyen complicitivamente a su propia dominación los grupos que continúen hablando con la voz que les ha sido asignada por aquellos que las han construido. De allí que el reclamo de un lenguaje inclusivo sea no sólo algo bueno para la construcción de las subjetividades masculina y femenina, sino algo necesario.

El poder falocrático se ejercita de manera sutil para no suscitar demasiadas protestas. Lo masculino aparece como un trasfondo, como un estándar implícito y, a primera vista, ausente. La mayoría de los psicólogos reconocen el papel importante que en la percepción de la figura juega el trasfondo $^{17}$. Este efecto también ha sido descrito en el área de las actitudes y de la percepción social ${ }^{18}$. En el lenguaje, lo masculino es el estándar preferido y el que se utiliza cuando existen géneros distintos en la construcción gramatical. El mensaje no por sutil deja de ser claro: lo femenino se antoja como inferior a lo masculino o como una manifestación negativa del término dominante. El estándar marcado es implícito aunque sea la base sobre la que se fundamenta la descripción ${ }^{19}$. La voz de la mujer es secundaria y se define en términos de ese estándar en cuya comparación siempre

13. Para un análisis más detallado sobre género e influencia social, ver Eagly, A. H., "Gender and social influence. A social psychological analysis", American Psychologist, 1983, pp. 971-981. Ver también a Lippa, R. y Connelly, S.. "Gender diagnosticity: a new bayesian approach to gender-related differences", Journal of Personality and Social Psychology, 1990, Vol. 59, pp. 1051-1065.

14. Ver Bourdieu, P. y Wacquant, L. J. D., An invitation to reflexive sociology, Chicaco: Chicago University Press, 1992; y Wilson, E. O., Sociobiology: The new synthesis, Cambridge, MA: Harvard University Press, 1975.

15. Ver Foucault, M., The history of sexuality: Vol I. An introduction, Nueva York: Random, 1980.

16. [The process of categorization, and thus the psychology of categorization, reside, not just in the mind, but... within discourse as part of a collective domain of negotiation, debate, argumentative and ideological struggle]. Wetherell, M. y Potter, J., Op. Cit., p. 77.

17. Para un explicación del principio gestáltico del fondo en la percepción de los objetos físicos ver Osgood, C. E., Method and theory in experimental psychology. Nueva York: Oxford University Press, 1953.

18. Ver Wyer Jr., R. S. y Carlston, D. E., "The cognitive representation of persons and events". En R. S. Wyer y T. K. Srull (Eds.). Handbook of social cognition, 2da Edición, Vol. 1: Basic Processes, Hillsdale, New Jersey: Lawrence Earlbaum, 1994, pp. 41-98; Clark, L. F., "Social cognition and health psychology". En R. S. Wyer y T. K. Srull (Eds.). Handbook of social cognition, 2da Edición, Vol. 2: Applications, Hillsdale, New Jersey: Lawrence Earlbaum, 1994, pp. 239-288; Hamilton, D. L. y Sherman J. W., "Stereotypes", En R. S. Wyer y T. K. Srull (Eds.). Handbook of social cognition, 2da Edición, Vol. 2: Applications, Hillsdale, New Jersey: Lawrence Earlbaum, 1994, pp. 1-68.

19. Igual distinción aparece en la filosofía a partir de la dicotomía cartesiana de mente y cuerpo. Lo que se presenta como una distinción entre una categoría (mente) y otra (cuerpo) toma la forma de " $A$ " (mente) y "No A" (cuerpo). Esta observación está explayada extensamente en Gatens, M., Feminism and philosophy: Perspectives on difference and equality, Cambridge, Gran Bretaña, Polity Press, 1991. 
sale perdiendo. Digámoslo de otro manera. Nuestras descripciones no sólo son juicios evaluativos, sino que el estándar implícito utilizado en tales juicios es el resultado del poder y sirve para mantenerlo.

\section{Conclusión}

La insistencia de mucha mujeres - pero no sólo mujeres- de que nuestro lenguaje debe de ser más inclusivo es un reclamo para poder tener una voz en la construcción de su identidad desde sus experiencias propias. Es una llamada para hacernos a todos y a todas conscientes de que esto no puede lograrse sino desde el ámbito de la igualdad, y que, por lo tanto, existe una imperiosa necesidad de denunciar todo intento acomodaticio que le robe al lenguaje su función transformadora. La identidad se va construyendo discursivamente y de allí la urgencia de ser protagonistas en la edificación de este discurso. No ayuda mayormente a cimentar una conversación dialógica equitativa el pensar que sí o que no se necesita cambiar el lenguaje, o si hay que hacerlo excesivamente oneroso o ridiculizarlo.

Un objetivo igualmente importante para rectificar el lenguaje es transformar las relaciones de poder que permiten a un grupo determinar la voz y la vida de otro. De obtenerse este objetivo, el impacto sería grande ya que se exigiría el establecimiento de relaciones diferentes para que se dé una verdadera colaboración discursiva. No se trata de que unas se derritan y amolden al punto de vista de los otros de tal manera que pierdan su perspectiva idiosincrática. No se trata tampoco de transformar a la otra persona mediante imágenes que aseguran su sometimiento. Se trata principalmente de habitar en una esfera de comunicación genuinamente dialógica, donde personas con distintas perspectivas se entiendan como iguales en el proceso discursivo de donde surge un mundo para todos y todas unido.

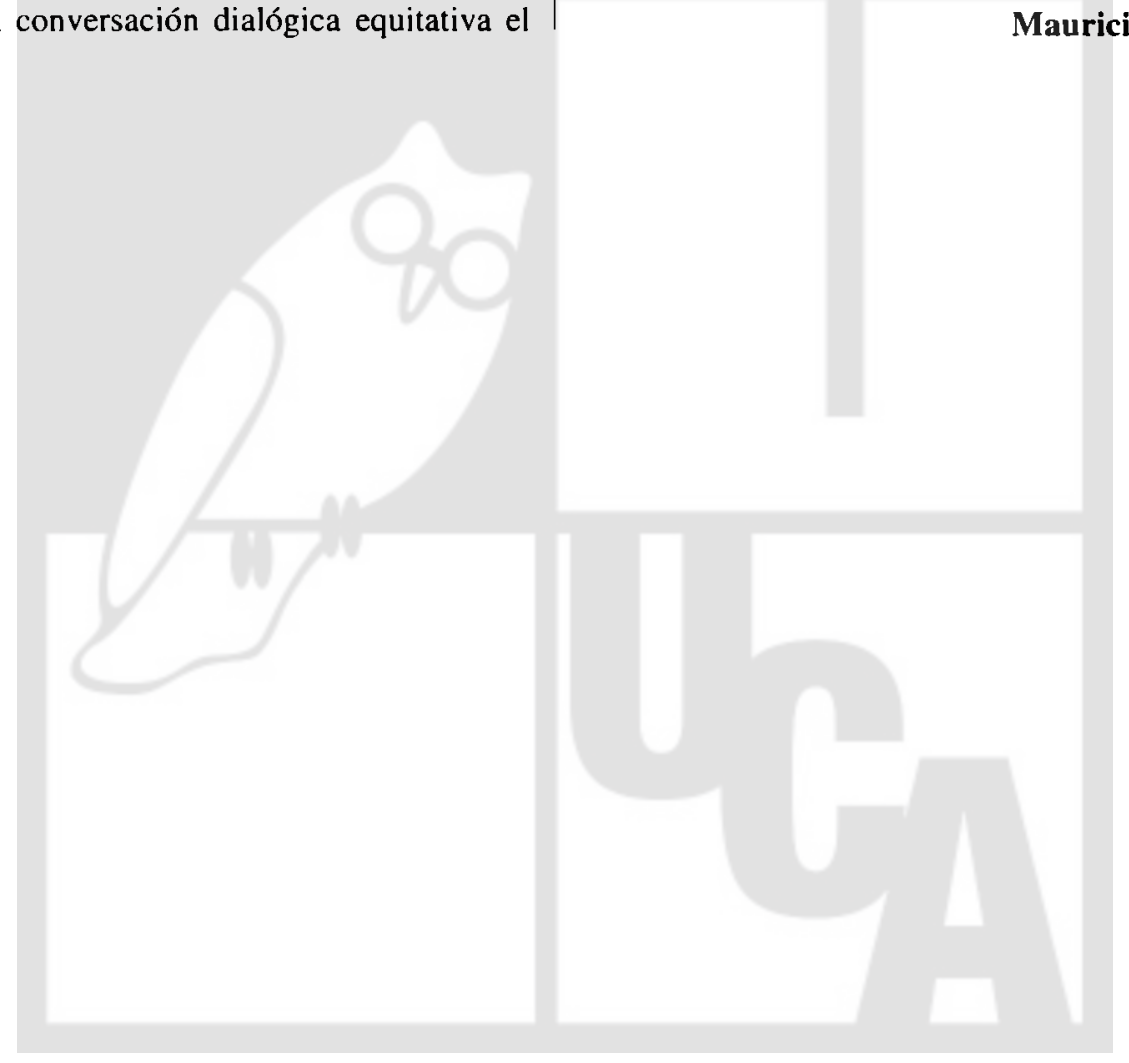

* Jefe del Departamento de Psicología de la Universidad Centroamericana "José Simeón Cañas", UCA. 